\title{
O PERCURSO DOLOROSO ENTRE A PRÁTICA E A TEORIA: REFLEXÕES SOBRE A PERSONAGEM URANIA EM "A FESTA DO BODE”, DE MARIO VARGAS LLOSA
}

\author{
Eduardo Marks de Marques* \\ Raíssa Cardoso Amaral ${ }^{* *}$ \\ Universidade Federal de Pelotas
}

\begin{abstract}
Resumo: Este artigo irá apresentar reflexões sobre a personagem Urania do romance $A$ Festa do Bode, publicado originalmente em 2000, pelo escritor peruano Mario Vargas Llosa. Para esta análise, utilizou-se o conceito de metaficção historiográfica, cunhado por Linda Hutcheon ([1998] 1991) para abordar a relação entre literatura e história no romance. No que concerne à análise da personagem Urania (foco primordial do artigo) será demonstrado o entrelaçamento de memória e trauma no eixo narrativo de Urania, já que a personagem passou por uma experiência traumática em um período limite da República Dominicana: a ditadura da Era Trujillo (1930-1961). No percurso entre a teoria e prática, isto é, a vivência histórica e o conhecimento histórico, eis que surge Urania e o poder de recriar ficcionalmente as consequências que a $\mathrm{d}$ itaduras podem deixar nos indivíduos. Além disso, é justamente no movimento entre teoria e prática que a reconstrução da identidade dominicana de Urania torna-se possível.
\end{abstract}

Palavras-chave: Urania. Memória. Experiência traumática. Mario Vargas Llosa

Este artigo irá abordar a relação entre literatura e história no romance $A$ Festa do Bode (Título original: La Fiesta del Chivo) do escritor peruano Mario Vargas Llosa,

Esta obra está licenciada sob uma Creative Commons - Atribuição 4.0

\footnotetext{
* Possui graduação em Licenciatura em Letras - Português e Inglês pela Universidade Federal do Rio Grande do Sul (1999), mestrado em Letras (Inglês e Literatura Correspondente) pela Universidade Federal de Santa Catarina (2002), doutorado em Australian Literature and Cultural History - University of Queensland (2007) e pós-doutorado em Estudos Literários, ênfase em Teoria Literária pela Universidade Federal de Minas Gerais (2014). Atualmente é Professor Adjunto nível 4 da Universidade Federal de Pelotas Tem experiência na área de Letras, com ênfase em Literatura Australiana e estudos de distopias, pós-humanismo e transumanismo, atuando principalmente nos seguintes temas: história australiana, estudos culturais australianos, estudos australianos, história cultural e teorias literárias e culturais, literatura distópica, transumanismo e pós-humanismo. E-mail: <eduardo.marks@mandic.com.br>.

** Mestranda na área de Literatura Comparada no Programa de Pós-Graduação em Letras da Universidade Federal de Pelotas, com bolsa CAPES. Graduada no curso de Licenciatura em Letras - Português e Literaturas de Língua Portuguesa pela Universidade Federal de Pelotas (2014). E-mail: < issa.amaral@hotmail.com>.
} 
publicado originalmente em $2000^{1}$. O recorte específico desta análise é o eixo narrativo da personagem Urania e seu entrecruzamento com a memória e o conhecimento teórico adquirido, isto é, como ocorreu o processo de percepção da vivência em um período limite da história da República Dominicana - a ditadura da Era Trujillo (1930-1961) - e o quanto isso afetou sua vida ao longo dos anos.

A estrutura da narrativa é formada por eixos em paralelo que estão organizados da seguinte maneira: inicialmente nos é apresentado o eixo com maior teor literário (eixo de Urania) e nos outros dois eixos há uma aproximação maior com os dados históricos oficiais (eixos de Trujillo e dos revolucionários que planejam a morte do ditador, respectivamente). Outra informação relevante a respeito dos eixos é a seguinte: o eixo de Urania é o único situado no tempo presente que equivale ao ano de 1996 na narrativa, já os outros dois eixos estão situados nos últimos dias da ditadura de Trujillo, entrelaçados pelo dia 30 de maio de 1961 que corresponde à data do assassinato do ditador.

Os meandros existentes entre realidade e ficção estão emaranhados em $A$ Festa do Bode. Em uma entrevista concedida a Isabel Vieira via telefone para uma revista brasileira, ao ser questionado se Urania realmente existiu, Vargas Llosa afirmou "Urania é imaginária, um personagem simbólico ${ }^{2}$." Esse tipo de confirmação de que estamos no campo literário é sintomática, pois significa que $A$ Festa do Bode causou desconfiança ao leitor comum sobre o gênero no qual se encaixaria o que foi lido.

No texto "Considerações sobre o Romance Histórico" (1994), Marilene Weinhardt considera György Lukács como essencial para a compreensão deste tipo específico de romance e, conforme as ideias do filósofo húngaro, a origem do romance histórico está situada no início do século XIX, com Walter Scott. A visão marxista de Lukács explicita que a importância não reside na noção de história como pano de fundo da narrativa, mas no impacto dos dados históricos no homem comum e, por isso, defende a ideia de que o romance histórico é necessariamente social.

A visão defendida por Marilene Weinhardt (1994) vai ao encontro da afirmação mencionada acima de Lukács: no romance histórico há um impacto poético que surge dos personagens que vivenciaram as experiências históricas. Na apresentação intitulada "A história e as formas" para a tradução de O romance histórico de György Lukács para o português (Editora Boitempo, 2011), Arlenice Almeida da Silva comenta que

\footnotetext{
${ }^{1}$ A edição do romance $A$ Festa do Bode utilizada neste ensaio é do ano de 2011 (Tradução de Ari Roitman e Paulina Wacht), publicada pela Editora Objetiva, com selo da Alfaguara.

${ }^{2}$ Disponível em: http://isabelvieira.com.br/?articles=ditadura-nunca-mais. (Janeiro de 2001)
} 
Do ponto de vista da história da literatura ou da crítica de arte, o esquema lukacsiano sugere que as obras que coincidem com mudanças históricas significativas formam um fluxo que as interliga aos acontecimentos, que é constituído em momentos ontológicos da evolução da humanidade. (SILVA, 2011, p.22).

No entanto, os critérios de romance histórico propostos por Lukács na publicação do livro O romance histórico (1936-1937 em russo; 1954 em alemão) já não conseguem dar conta de toda a ficção contemporânea. Surgem, então, novas propostas de olhar para a relação entre literatura e história como, por exemplo, o livro Meta- História: A Imaginação Histórica do Século XIX de Hayden White ([1973] 2008) e o termo "metaficção historiográfica" cunhado por Linda Hutcheon no livro Poética do Pós-Modernismo: história, teoria e ficção ([1988] 1991).

Na introdução do livro de Hayden White intitulada "A Poética da Histórica" o autor afirma que as possíveis formas de aproximação entre literatura e história ocorrem a partir de técnicas linguísticas e, a partir desta constatação, desestrutura o próprio discurso histórico e questiona o objetivo e status da história como disciplina, afinal, "[...] as disputas sobre o que a "história" deve ser refletem de igual modo variadas concepções daquilo em que deve consistir uma correta explicação histórica e diferentes concepções, portanto, da tarefa do historiador." (WHITE, 2008, p. 28). No capítulo "Verdade e memória do passado" do livro Lembrar Escrever Esquecer, Jeanne Marie Gagnebin também solicita que lembremos a "[...] preciosa ambiguidade do próprio conceito de história, em que se ligam, indissociavelmente, o agir e o falar humanos: em particular a criatividade narrativa e a inventividade prática." (GAGNEBIN, 2006, p. 43, grifos do autor).

Na leitura proposta neste ensaio, A Festa do Bode é considerada uma metaficção historiográfica. A justificativa para o uso desta terminologia está relacionada aos romances que “[...] são intensamente auto-reflexivos e mesmo assim, de maneira paradoxal, também se apropriam de acontecimentos e personagens históricos." (HUTCHEON, 1991, p. 21). Marilene Weinhardt afirma que a metaficção historiográfica "[...] já não se confunde com a ficção histórica por comportar uma aguda autoconsciência de seu processo de constituição.” (1994, p. 58). Sobre este viés, A Festa do Bode é um romance que se apropria do discurso da história oficial ${ }^{3}$ da República Dominicana (e de personas históricas também) para discutir outras questões, no campo literário, tais como a construção/reconstrução de uma identidade dominicana.

Urania - o foco principal de análise - faz um movimento de sair da prática para a

\footnotetext{
${ }^{3} \mathrm{O}$ termo "história oficial" utilizado neste artigo refere-se àquela construção histórica suportada pelo regime ditatorial na República Dominicana.
} 
teoria, ou seja, após experiência traumática vivenciada em sua adolescência na Era Trujillo (período ditatorial da República Dominicana), ela realiza um autoexílio existencial e viaja aos Estados Unidos, com o auxílio de uma freira, sister Mary. É lá, distante de Santo Domingo 4 , sua terra natal, que Urania estuda intensamente o período de exceção da República Dominicana indo à minicursos, lendo livros e artigos, entre outras atividades voltadas para o estudo teórico deste momento específico da história dominicana. Urania age apenas como observadora/ouvinte, sem jamais dar seu testemunho e seu pai, Agustín Cabral, aparece como personagem nas leituras que realiza:

\begin{abstract}
Meu apartamento em Manhattan está cheio de livros [...] Mas no meu quarto, só livros dominicanos. Depoimentos, ensaios, memórias, muitos livros de história. Adivinhe de que época. Da era Trujillo, que outra podia ser. A coisa mais importante que nos aconteceu em quinhentos anos. Você falava isso com tanta conviç̧ão. [...] Em alguns desses livros você aparece, como personagem. Secretário de Estado, senador, Presidente do Partido Dominicano. Há alguma coisa que você não tenha sido, papai? Eu me tornei especialista em Trujillo. (LLOSA, 2011, p. 59-60).
\end{abstract}

Desse modo, a personagem renega seu envolvimento pessoal em uma época de autoritarismo, apenas mantém o contato com Santo Domingo e a história oficial por meio dos textos. Pode-se considerar que Urania está suspensa no tempo, seu vínculo com a noção de República Dominicana é exclusivamente acadêmico e o retorno é emblemático: a demora de trinta e cinco anos para "colocar os pés" em Santo Domingo é significativa. Carla Rosane da Silva Tavares afirma, em sua tese, que

[...] o romance de Llosa, no decorrer de suas páginas, permite um duplo retorno: o da cidadã dominicana, afastada da pátria há trinta e cinco anos, e o de Trujillo com as personagens e acontecimentos que determinaram sua morte. Abrem-se, assim, duas páginas: uma literária e uma histórica. (TAVARES, 2007, p. 163).

Kathryn Woodward ressalta que "As posições que assumimos e com as quais nos identificamos constituem nossas identidades.” (2014, p. 16). Nesse sentido, percebemos o quanto há um esfacelamento da identidade dominicana de Urania e uma tentativa de reconciliação com esta cultura, justificada principalmente pelo retorno a Santo Domingo, depois de vários anos afastada, sem dar notícia alguma para os familiares. A tese de doutorado intitulada A perspectiva da mulher como resistência às configurações ideológicas do ditador latino-americano: o romance de Julia Alvarez e de Mario Vargas Llosa ${ }^{5}$ reconhece que

\footnotetext{
${ }^{4}$ Entre 1930 e 1961, Santo Domingo era denominada "Cidade de Trujillo".

${ }^{5} \mathrm{O}$ corpus literário da tese de Doutorado citada são os romances No Tempo das Borboletas (1994), de Julia Alvarez e A Festa do Bode (2000), de Mario Vargas Llosa.
}

Anu. Lit., Florianópolis, v. 21, n. 1, p. 32-45, 2016. ISSNe 2175-7917 
[...] há uma articulação plena da verdade histórica e da composição poética nas narrativas de Alvarez e de Vargas Llosa. [...] os textos promovem um diálogo com a História, revelando, em sua construção, formas de engendramento das identidades sociais de um país ferido pela opressão política. (TAVARES, 2007, p. 198)

O próprio repensar sobre a área da história está vinculado ao fato de visualizar o discurso histórico como algo da criação humana e acessado na forma textual: "O pósmodernismo não nega a existência do passado, mas de fato questiona se jamais poderemos conhecer o passado a não ser por meio de seus restos textualizados" (HUTCHEON, 1991, p. 39, grifos do autor). A partir dessa visão pós-moderna, o acesso ao entendimento da história está relacionado à ideia de que tanto a história como a ficção são discursos e possuem em comum a linguagem, traduzida em vestígios textuais.

Ao propor uma poética do Pós-Modernismo e o termo "metaficção historiográfica", Linda Hutcheon argumenta que "A metaficção historiográfica não pretende reproduzir acontecimentos, mas, em vez disso, orientar-nos para os fatos, ou para novas direções a tomar, para que pensemos sobre os acontecimentos." (HUTCHEON, 1991, p. 198). Em conformidade com as ideias de Hutcheon, Cláudia Paulino de Lanis também defende que o romance de Vargas Llosa é pós-moderno, pois "La Fiesta del Chivo questiona e repensa não só a ditadura da República Dominicana, mas também todas as ditaduras da América Latina, intertextualizando, representando o híbrido, o plural e o heterogêneo deste tema." (LANIS, 2005, p. 31).

No romance de Mario Vargas Llosa aqui analisado, há o entendimento de que vivência histórica e conhecimento histórico são noções completamente diferentes. Urania possuía a vivência, mas renunciou sua própria existência como cidadã dominicana. $\mathrm{O}$ retorno de Urania após sua diáspora é impactante, afinal, após trinta e cinco anos de contato com Santo Domingo apenas pelo meio textual, ela retorna a Santo Domingo "de carne e osso": “ Fecha os olhos, dominada por uma inércia que não era comum nela, acostumada a estar sempre em atividade, a não perder tempo fazendo aquilo que, desde que pôs os pés em terra dominicana, ocupa sua mente noite e dia: lembrar." (LLOSA, 2011, p. 13)

No pai de Urania, Agustín Cabral (Craninho), ocorre um processo de morte em vida por duas vias: uma referente ao derrame (AVC) e uma morte simbólica no período ditatorial, quando Trujillo o retirou de seu círculo de amizade sem justificativa alguma, possivelmente por fofocas de outros seguidores de Trujillo. Urania caracteriza a morte dos pais da seguinte forma: “[...] sua mãe estava no céu e o pai, morto em vida.” (LLOSA, 2011, p. 11). Urania, em uma espécie de monólogo para acertar pendências do passado, enfrenta o pai, impossibilitado de falar (devido às consequências do derrame) e questiona fatos que poderiam 
ter acontecido como, por exemplo, se sua mãe havia sido "visitada" por Trujillo6:

O Chefe visitou a minha mãe? Antes de eu nascer? Quando era pequena demais para lembrar? Ele fazia isso quando as esposas eram bonitas. [...] As boas dominicanas ficavam até gratas se o Chefe se dignava a comê-las. Acha isso uma vulgaridade? Mas era esse o verbo que o seu querido Chefe usava. Sim, esse mesmo. Urania sabe, tinha lido na sua vasta bibliografia sobre a Era Trujillo [...] (LLOSA, 2011, p. 64).

No eixo dos revolucionários, cada homem que planeja a morte de Trujillo ${ }^{7}$ possui uma justificativa pessoal ${ }^{8}$ para o ato. Amadito não pôde casar com Luisa Gil porque Trujillo se opôs "Embora nunca mais a tenha visto, não a substituiu no coração." (LLOSA, 2011, p. 44) e, cruelmente, ainda fez com que Amadito carregasse a dúvida se havia ou não matado o irmão de Luisa; Antonio de La Maza quer vingar a morte do irmão "Depois do que aconteceu com Tavito, ele perdera todas as ilusões, todo o entusiasmo, todo o amor por esta vida ou outra. Era a ideia de vingança que o mantinha ativo [...]" (LLOSA, 2011, p. 104). Amadito, Antonio de La Maza, Antonio Imbert, Salvador Estrella Sadhalá eram infiltrados no governo de Trujillo e o plano para "cercar" Trujillo na estrada era o maior objetivo de suas vidas. O trecho abaixo (Capítulo IX, narrado por Antonio Imbert $^{9}$ ) é um fragmento do pensamento de Imbert que passara a vida trabalhando para Trujillo:

Quanta coisa havia acontecido na República Dominicana, no mundo e na sua vida pessoal. Muita coisa. As prisões em massa de janeiro de 1960, quando caíram tantos rapazes e moças do Movimento 14 de Junho, entre os quais as irmãs Mirabal e seus maridos. O rompimento de Trujillo com sua antiga cúmplice, a Igreja Católica, a partir da Carta Pastoral dos bispos, denunciando a ditadura, de janeiro de 1960. O atentado de junho de 1960 contra o Presidente Betancourt, da Venezuela, que mobilizou tantos países contra Trujillo, inclusive o seu grande aliado de sempre, os Estados Unidos, que, em 6 de agosto de 1960, na Conferência da Costa Rica, votaram a favor das sanções. E, em 25 de novembro de 1960 [...] o assassinato das três irmãs, Minerva, Patria e María Teresa Mirabal [...] (LLOSA, 2011, p. 159).

Aliás, as narrativas dos eixos do romance se interconectam diversas vezes, pois Urania rememora os fatos que ocorreram nos outros dois eixos do romance como, por exemplo, neste fragmento do Capítulo X:

Então também foi preso [Agustín Cabral], após a morte de Trujillo. Pensaram que

\footnotetext{
${ }^{6}$ Trujillo não era apenas o detentor do poder em Santo Domingo, mas também possuía os corpos femininos de Santo Domingo. Os homens se sentiam honrados quando Trujillo desejava suas esposas e filhas, mas alguns cidadãos dominicanos conscientes temiam este desejo do "Chefe".

${ }^{7}$ Esta ação, no romance, ocorre em 30 de maio de 1961, dado histórico que condiz com a data do assassinato do ditador Rafael Leonídas Trujillo Molina.

${ }^{8} \mathrm{~A}$ intenção deste ensaio não é descrever minuciosamente as motivações que levaram os sete homens envolvidos no complô a desejarem a morte de Trujillo. Para fins de exemplificação, apresentamos as justificativas de Amadito e Antonio de La Maza, pois elas demonstram que a crueldade da ditadura atingia a vida pessoal, amorosa e familiar dos indivíduos.

${ }^{9}$ No trecho selecionado do pensamento de Antonio Imbert percebe-se a extrema relevância dos dados históricos para contextualização do leitor que está nas páginas de $A$ Festa do Bode.
}

Anu. Lit., Florianópolis, v. 21, n. 1, p. 32-45, 2016. ISSNe 2175-7917 
era um dos trujillistas que conspiraram com Antonio de La Maza, o general Juan Tomás Díaz e seu irmão Modesto, Antonio Imbert e companhia [...] Ela soube que seu pai tinha sido preso muitos anos depois, por uma menção de passagem, num artigo sobre acontecimentos dominicanos de 1961. (LLOSA, 2011, p. 183).

Dessa forma, os episódios importantes ocorridos tanto na família Cabral como, por exemplo, o período que Agustín Cabral passou na prisão de La Cuarenta, e os fatos da história oficial de Santo Domingo só eram acessados por Urania a partir de textos. Aliás, a notícia sobre o assassinato de Trujillo chega até Urania através de uma manchete de jornal, pois ela já estava morando na cidade de Adrian (Michigan): “[...] a sister encarregada do dormitory entrou no quarto que Urania dividia com quatro colegas e lhe mostrou a manchete de jornal que trazia a mão: Trujillo killed." (LLOSA, 2011, p. 185).

A proposta do título A Festa do Bode possui consideráveis leituras interpretativas. Uma possível leitura do título possui relação com a história pessoal da personagem Urania e outra se encontra disponível, logo no início do romance, na epígrafe "O povo festeja com grande entusiasmo a Festa do Bode em trinta de maio" Mataram o Bode - merengue dominicano. Esta via interpretativa é uma alusão à festa histórica da morte do "Bode", ou seja, comemoração da libertação. Outro paratexto evidente é a imagem da capa Alegoría del mal gobierno (fragmento) retratar um demônio, figura emblemática associada ao bode.

No capítulo II (primeiro capítulo do eixo Trujillo), há um intertexto bíblico explícito do poder que emana de Trujillo em comparação a Jesus Cristo, uma entidade que possui poderes não explicáveis: "Trujillo podia fazer água se transformar em vinho e pães se multiplicarem, se lhe desse na telha." (LLOSA, 2011, p. 26). Poder mistificado que deriva de Trujillo, mas não condiz com sua decadência corporal evidenciada pela incontinência urinária, causada por uma doença na próstata: "Lá estava: a mancha escura se estendia pela braguilha [...] Podia dominar os homens, pôr de joelhos três milhões de dominicanos, mas não podia controlar o próprio esfíncter." (LLOSA, 2011, p. 145).

Entretanto, é a leitura do título do romance com a narrativa pessoal de Urania que nos interessa: Urania sofre uma violência real nas mãos do mantenedor do regime ditatorial. Em sua inocência, Urania acredita nas palavras de seu pai e, por isso, aceita a ideia de ter sido convidada para uma festa pelo ditador Rafael Leonídas Trujillo. O encontro com o ditador é um evento limite: o estupro extermina a identidade dominicana de Urania, a desfigura culturalmente. Para o encontro com o "Chefe", Urania está sexualizada, com as joias da mãe, praticamente uma oferenda a uma entidade de poder, no caso, Trujillo: "Naquela noite, fiz um monte de coisas pela primeira vez: beber xerez, usar as joias da mamãe, dançar com um velho de setenta anos [Trujillo] e receber meu primeiro beijo na boca." (LLOSA, 2011, p. 437-438).

Anu. Lit., Florianópolis, v. 21, n. 1, p. 32-45, 2016. ISSNe 2175-7917 
Gabriela Maldonado e Marta Rezende Cardoso em artigo dedicado ao conceito de trauma comentam sobre as particularidades de uma memória traumática: "[...] ela é literal (repete o mesmo), imemorável (passado é presente), inumana (da ordem das marcas, e não dos traços significativos). [...] No imemorável do trauma, o tempo passado é "cristalizado" no tempo presente [...]" (2009, p. 5). A partir das ideias de Freud, expostas no artigo citado, o trauma é um evento que desconstrói nossa posição de ser humano e a superação pode ser buscada através do discurso.

No livro Lembrar Escrever Esquecer, o conceito de trauma refere-se a uma "[...] ferida aberta na alma, ou no corpo, por acontecimentos violentos, recalcados ou não, mas que não conseguem ser elaborados simbolicamente, em particular sob a forma de palavra, pelo sujeito." (GAGNEBIN, 2006, p. 110). O narrador onisciente, nos diálogos metaficcionais que estabelece com Urania, adverte que ela "Poderia ter feito terapia, recorrer a um psicólogo, um psicanalista. Eles têm remédio para tudo [...] Mas você nunca quis se curar." (LLOSA, 2011, p. 185).

Urania não consegue falar sobre o ocorrido por trinta e cinco anos e o monólogo com o pai é seu único modo de confronto. Para Urania, a historiografia, isto é, o acesso textualizado à história dominicana, funciona como superação do trauma, mas é apenas uma superação parcial. A tentativa de superar de uma vez por todas o trauma é no confronto com o pai doente, sem possibilidade de conversar com ela. Aliás, Urania deixa claro que não deseja uma conciliação nem irá perdoar o pai:

E o que aconteceu comigo, conosco, apagou [da memória] também? Eu não. Não deixei de pensar nisso um só dia. Nestes trinta e cinco anos, papai. Nunca esqueci, nem o perdoei. [...] Sabe por que eu nunca pude perdoá-lo? Porque você nunca se lamentou de verdade. Depois de tantos anos servindo ao Chefe, havia perdido os escrúpulos, a sensibilidade, qualquer vestígio de retidão. (LLOSA, 2011, p. 121).

O mistério que justificaria o abandono (local e familiar) de Urania só nos é exposto nos últimos capítulos do eixo de Urania em A Festa do Bode, porém há indícios interpretativos do que havia acontecido de tão grave com ela, afinal, o monólogo citado acima está inserido justamente no meio da narração do estupro coletivo de Rosalía Perdomo, filha de um coronel do Exército:

Em vez de jogá-la numa vala, no meio do campo, como teriam feito se Rosalía não fosse uma Perdomo, menina branca, loura, rica e de respeitada família trujillista [...] eles agem com consideração. [...] Parece que o pobre coronel Perdomo nunca se recuperou do trauma de saber que sua adorada filha tinha sido tranquilamente ultrajada por Ramfis Trujillo e seus amigos entre o almoço e o jantar, como quem mata o tempo vendo um filme. (LLOSA, 2011, p. 120). 
Para Jeanne Marie Gagnebin, a memória estabelece uma “[...] tensão entre a presença e a ausência, presença do presente que se lembra do passado desaparecido, mas também presença do passado desaparecido que faz sua irrupção em um presente evanescente." (GAGNEBIN, 2006, p. 44). Sobre a representação da importância da memória para compreendermos a personagem Urania, temos a seguinte passagem "Urania sempre foi fascinada por esses estranhos meandros da memória, as geografias que ela constrói em função de estímulos misteriosos, de associações imprevistas." (LLOSA, 2011, p. 124). Logo adiante, Urania admite o quanto suas lembranças lhe causam desconforto: "Isso que estou fazendo aqui, divagar, cavar lembranças, é uma coisa que não faço nunca. [...] Não tenho tempo para ficar monologando sobre a história dominicana.” (LLOSA, 2011, p. 128).

No reencontro com a prima Lucinda, Urania relembra o final de maio de 1961, os quatro anos de estudo em Michigan, na Siena Hights University e sister Mary “[...] a única pessoa com quem Urania se abriu, que teve a luminosa ideia de tirá-la de lá [Santo Domingo] e mandá-la para Adrian [...]" (LLOSA, 2011, p. 175). No capítulo XVI, temos a descrição do momento em que Urania decide contar para sua tia Adelina e as duas primas (Lucindita e Manolita), a experiência traumática que a fez sair de Santo Domingo às pressas e não responder nenhuma carta ou manter contato com algum familiar: "Essa história me incomoda e me dá náuseas [...] Sempre me enche de ódio e de nojo. Nunca contei a ninguém. Talvez me faça bem livrar-me disso, de uma vez por todas.” (LLOSA, 2011, p. 296).

O leitor atento irá lembrar que apenas sister Mary ${ }^{10}$ sabia o motivo pelo qual Urania abandonou Santo Domingo. Portanto, ao afirmar que nunca havia contado a ninguém, duas hipóteses especulativas aparecem: ou os lapsos da memória estão presentes em Urania ou a personagem opta por não contar para as mulheres de sua família que já havia contado para sister Mary.

Manuel Alfonso é um dos homens que aliciam mulheres para Trujillo e é ele quem incentiva Agustín Cabral a oferecer a virgindade de Urania para recuperar a confiança do "Chefe". Ao comparar Trujillo com um Deus e compará-lo com Carlos Magno, Napoleão e Bolívar, Manuel Alfonso diz que "nada [o] daria mais satisfação, mais felicidade, que ver o Chefe fazer uma filha [sua] gozar, e gozar com ela." (LLOSA, 2011, p. 299). Agustín Cabral aceita este cruel conselho, porém o sacrifício é em vão, afinal, entrega sua única filha ao "Chefe" para tentar retornar ao regime, mas isso não acontece.

Para convencer a filha de quatorze anos a comparecer em um encontro sexual com

${ }^{10}$ Ver a citação da p. 175 do romance $A$ Festa do Bode, transcrita nesta página do ensaio. 
Trujillo, Agustín Cabral inventa que Trujillo havia convidado apenas Urania para uma festa, sem dar muitas explicações, o que deixa Urania confusa, pois na época ela ainda era inocente: “[...] ela era uma menina normal e saudável - o último dia que você seria assim, Urania devoradora de romances e, de repente, essa festa [...]" (LLOSA, 2011, p. 306). Ao relatar para as mulheres da família o que realmente aconteceu, Urania "vomita" toda a sua angústia de ter passado pela experiência repulsiva, três décadas passaram e ela não digeriu nada: “- Quem mais convidaram para essa festa? - Olha para tia Adelina, Lucindita e Manolita: - Só para ver o que ele [Manuel Alfonso] respondia. Eu já sabia que não íamos a festa nenhuma.” (LLOSA, 2011, p. 431).

Trujillo, na época, com setenta anos e com uma doença na próstata, coloca a culpa em Urania por sua impossibilidade de realizar o ato sexual, mas resolve a estuprar com os dedos, como seu irmão Petán fazia: "Os mesmos dedos das mãos que assinavam papéis presidenciais invadiam destrutivamente, sem piedade e pudor, as partes íntimas de uma menina [Urania]." (TAVARES, 2007, p. 182). Trujillo deixa Urania sair viva da Casa de Caoba (local onde ele realizava seus encontros sexuais), mas antes de sair, Urania presencia Trujillo fragilizado, chorando por não ter o poder sexual que todos os dominicanos pensavam que ele possuía. Porém, o olhar de Trujillo, após ter chorado, ainda permanece na memória de Urania: "Eu tenho quarenta e nove anos e, quando penso nisso, ainda tremo. Passei trinta e cinco anos tremendo, desde aquele momento." (LLOSA, 2011, p. 443).

No artigo intitulado "O trauma psíquico e o paradoxo das narrativas impossíveis, mas necessárias" já utilizado nesta análise, há comentários sobre

[...] o duplo aspecto que o trauma comporta: a impossibilidade e a necessidade de sua representação. Diante do traumático, um testemunho se assenta necessariamente sobre a experiência-limite de um narrador que perfurou a barreira entre a vida e a morte. (MALDONADO; CARDOSO, 2009, p. 6).

A ideia do título do artigo mencionado acima faz referência ao livro Lembrar Escrever Esquecer de Jeanne Marie Gagnebin (2006) no qual a autora argumenta sobre "[...] as narrativas - simultaneamente impossíveis e necessárias, nas quais a memória traumática, apesar de tudo, tenta se dizer [...]" (GAGNEBIN, 2006, p. 44). A narrativa de Urania sobre o estupro cometido pelos dedos do "todo-poderoso" Chefe, Benfeitor da Pátria, sua Excelência - entre tantos outros apelidos que Trujillo recebeu - é, neste ensaio, considerada uma narrativa impossível, mas necessária, afinal, o sofrimento de Urania representa ficcionalmente o sofrimento de todos os indivíduos que sofreram consequências nas ditaduras que aconteceram na América Latina e, por isso, precisa ser ouvido/registrado, para que períodos 
históricos como esses não se repitam.

Há uma necessidade de ouvir a voz de Urania, ela não pode ser considerada apenas uma "versão" da história oficial. Urania recria ficcionalmente as diversas vítimas do regime autoritário e coube a ela (central no aspecto histórico da narrativa) contar o sofrimento de ter passado pela experiência traumática do estupro: "Outra pessoa poderia ter superado, talvez. Eu não quis, e nem pude." (LLOSA, 2011, p. 445). Ao falar sobre os sobreviventes de Auschwitz (mas podemos estender para os sobreviventes de regimes ditatoriais), Gagnebin ressalta que "É próprio da experiência traumática essa impossibilidade do esquecimento, essa insistência na repetição." (GAGNEBIN, 2006, p. 99).

No artigo "Literatura e história: os discursos da memória" a Prof. Dra. Rosani Ketzer Umbach afirma que "O ato de narrar imprime a marca do narrador e atualiza o tempo passado: tornando-o tempo vivo e pleno de significado." (UMBACH, 2010 p. 110), ou seja, a decisão de Urania de contar para as suas familiares o que aconteceu, faz com que elas percebam (e nós, leitores, também) o quanto aquela memória permanece intacta para Urania: “[...] em A festa do Bode a personagem feminina protagonista tem um propósito: resgatar e, de certa forma, exorcizar a história do ditador em sua vida.” (TAVARES, 2007 p. 205).

A reconstituição discursiva de Urania assemelha-se a tarefa de um historiador ao reconstruir os dados oficiais da história, mas no que concerne à personagem Urania é a sua história pessoal e como os tentáculos da ditadura dominicana impregnaram sua existência (e a de todos os dominicanos):

Talvez não entrassem tantos ladrões nas casas, nem houvesse tantos assaltantes nas ruas roubando bolsas, relógios e colares dos transeuntes. Mas se matava, espancava, torturava, e muita gente desaparecia. Inclusive as pessoas mais próximas ao regime. Por exemplo, o filhinho, o belo Ramfis, quantos abusos cometeu. (LLOSA, 2011, p. 114).

Em outra passagem do romance, Urania relembra as palavras de seu colega de trabalho, Steve Duncan, cansado de propor casamento, em uma noite de 1985 ou 1986 (a personagem não lembra exatamente o ano):

\footnotetext{
"Você é um bloco de gelo. Nem parece dominicana. Eu sou mais dominicano que você". [...] Uma acusação que ofenderia a qualquer dominicana Nós temos reputação de mulheres quentes, de imbatíveis no amor. Eu ganhei fama de ser o contrário: afetada, indiferente, frígida. (LLOSA, 2011, p. 184).
}

Como foi possível perceber na citação acima, na construção feminina de Urania não se pode deixar de considerar as seguintes ideias: Urania rejeita o papel de vítima do sistema (ela participa de encontros sobre a ditadura da República Dominicana nos Estados Unidos, 
mas não dá seu testemunho), também renuncia a sensualidade, característica marcante para a cultura dominicana, e a própria vida amorosa, pois a experiência traumática sofrida aos quatorze anos a marcou de uma forma extrema: "Nunca mais um homem voltou a botar as mãos em mim, desde aquela vez. Meu único homem foi Trujillo. [...] papai e Sua Excelência me transformaram num deserto.” (LLOSA, 2011, p. 445).

É no último capítulo ${ }^{11}$ que Urania começa a reposicionar seu papel na família e na cultura dominicana (trinta e cinco anos de afastamento é um tempo considerável). A reconstrução de Urania só é possibilitada pela desconstrução de Agustín Cabral que a havia entregado para Trujillo sem pensar no ato cruel que havia realizado: “[...] uma criança que se tornou mulher pela violência de seus dois pais: o biológico e o de todos os dominicanos." (TAVARES, 2007, p. 183).

Nas páginas finais do romance, Urania ainda questiona se foi correto ter falado sobre o sofrimento daquele momento passado que ela reviveu integralmente ao contar para a tia e as primas e se irá ou não reaproximar-se mais vezes “[...] daqueles resíduos de família que lhe restam?” (LLOSA, 2011, p. 447). Nesse sentido, o romance finaliza com Urania pensando em escrever para a sobrinha “'Se Marianita me escrever, vou responder a todas as cartas dela', decide." (LLOSA, 2011, p. 450), ou seja, um indício de que a reaproximação poderá seguir adiante.

Urania carrega consigo o fardo da história oficial e as consequências do período ditatorial em sua vida, isto é, as práticas destrutíveis do estupro e do engano, pois ela acreditou no que seu pai havia inventado para persuadi-la a ir a "festa" de Trujillo. Ao rememorar os fatos dolorosos do estupro que lhe retirou tudo, inclusive à identidade dominicana, Urania realiza um processo de "[...] não se esquecer do passado, mas também agir sobre o presente. A fidelidade ao passado, não sendo um fim em si, visa à transformação do presente." (GAGNEBIN, 2006, p. 55). Sendo assim, através da vivência histórica e do conhecimento histórico/teórico de Urania, a história passa a ser vista não apenas como um discurso fechado em si mesmo, institucionalizado, mas sim como algo que integra a vida, perpassa a existência dos indivíduos.

\section{Referências}

GAGNEBIN, Jeanne Marie. Lembrar escrever esquecer. São Paulo: Editora 34, 2006.

\footnotetext{
${ }^{11} \mathrm{O}$ eixo de Urania inicia e fecha o romance $A$ Festa do Bode. A leitura interpretativa condiz com o fato da voz de Urania ser a única que permanece, já que os protagonistas dos outros dois eixos não sobrevivem (eixo de Trujillo e dos revolucionários). O legado da ditadura dominicana permanece vivo na família Cabral, principalmente na memória de Urania.
} 
LANIS, Cláudia Paulino. A obra de Mario Vargas Llosa, La Fiesta del Chivo, e a multiplicidade de máscaras. 2005. 134 f. Dissertação (Mestrado em Letras Neolatinas, Língua Espanhola e Literaturas Hispânicas) - Programa de Pós-Graduação em Letras Neolatinas, Universidade Federal do Rio de Janeiro, 2005. Disponível em: $<$ http://www.dominiopublico.gov.br/download/texto/cp020242.pdf $>$. Acesso em: 01 jul. 2015.

LlOSA, Mario Vargas. A Festa do Bode. [Título original: La Fiesta del Chivo] Rio de Janeiro: Objetiva/Alfaguara, 2011.

"Ditadura nunca mais!". Entrevista concedida a Isabel Vieira para (Janeiro de 2001). Disponível em: <http://isabelvieira.com.br/?articles=ditadura-nunca-mais $>$. Acesso em: 20 jun. 2015

MALDONADO, Gabriela; CARDOSO, Marta Rezende. O trauma psíquico e o paradoxo das narrativas impossíveis, mas necessárias. Psicologia Clínica, Rio de Janeiro, v. 21. n. 1, 2009. Disponível em $\quad<$ http://www.scielo.br/scielo.php?pid=S010356652009000100004\&script=sci_arttext $>$. Acesso em: 20 jun. 2015.

HUTCHEON, Linda. Poética do Pós-Modernismo: história, teoria, ficção. Rio de Janeiro: Imago, 1991.

SILVA, Arlenice Almeida da. A história e as formas. In: LUKÁCS, György. O romance histórico. São Paulo: Boitempo, 2011. p. 9-26.

TAVARES, Carla Rosane da Silva. El Chivo: um contraponto com Las Mariposas. In: A perspectiva da mulher como resistência às configurações ideológicas do ditador latinoamericano: o romance de Julia Alvarez e de Mario Vargas Llosa. 2007. 230 f. Tese (Doutorado em Literatura Comparada) - Universidade Federal do Rio Grande do Sul. Porto Alegre, Rio Grande do Sul, 2007. Disponível em $<$ http://www.lume.ufrgs.br/handle/10183/12752>. Acesso em 10 jun. 2015.

UMBACH, Rosani Ketzer. Literatura e história: os discursos da memória. Fragmentos, Florianópolis, n. 39, p. 105-119, 2010.

WEINHARDT, Marilene. Considerações sobre o Romance Histórico. Letras, Curitiba, n. 43, p. 49-59, 1994.

WHITE, Hayden. Meta-História: A Imaginação Histórica do Século XIX. São Paulo: EdUSP, 2008.

WOODWARD, Kathryn. Identidade e diferença: uma introdução teórica e conceitual. In: SILVA, Tomaz Tadeu da (Org.). Identidade e diferença: A perspectiva dos Estudos Culturais. 14. ed. Petrópolis, RJ: Vozes, 2014, p. 7-72.

[Recebido em setembro de 2015 e aceito para publicação em dezembro de 2015] 
The painful pathway between theory and praxis: reflections on the character Urania in Mario Vargas Llosa's The Feast of the Goat

Abstract: The following article will present reflections about the character Urania in the novel The Feast of the Goat, originally published in 2000 by Peruvian writer Mario Vargas Llosa. To this analysis, the concept of historiographical metafiction, coined by Linda Hutcheon ([1998] 1991) was used to discuss the relations between literature and history in the novel. In what concerns the analysis of the character Urania (core of this article), the lathing of memory and trauma is central, since the character suffered a traumatic experience in a difficult era of the Dominican Republic: the Trujillo Era (1930-1961). On the pathway between theory and practice, that is, the historical living experience and the historical knowledge, stands Urania and the power to recreate, using fiction, the consequences that dictatorships can have upon individuals. Besides, it is exactly in the movement between theory and practice that the reconstruction of Urania's Dominican identity becomes possible.

Keywords: Urania. Memory. Traumatic experience. Mario Vargas Llosa.

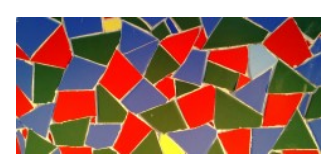

